AperTO - Archivio Istituzionale Open Access dell'Università di Torino

Patient-reported outcomes in the evaluation of toxicity of anticancer treatments

This is a pre print version of the following article:

Original Citation:

Availability:

This version is available http://hdl.handle.net/2318/1603135

since 2016-10-17T14:28:57Z

Published version:

DOI:10.1038/nrclinonc.2015.222

Terms of use:

Open Access

Anyone can freely access the full text of works made available as "Open Access". Works made available under a Creative Commons license can be used according to the terms and conditions of said license. Use of all other works requires consent of the right holder (author or publisher) if not exempted from copyright protection by the applicable law. 


\section{Patient-reported outcomes in the evaluation of toxicity of anticancer treatment.}

Massimo Di Maio ${ }^{1}$, Ethan Basch ${ }^{2}$, Jane Bryce ${ }^{3}$ and Francesco Perrone ${ }^{3}$.

${ }^{1}$ Department of Oncology, University of Turin, "San Luigi Gonzaga Hospital", Orbassano (TO), Italy .

${ }^{2}$ Cancer Outcomes Research Program, Lineberger Comprehensive Cancer Center, University of North Carolina, Chapel Hill, NC 27599, USA.

${ }^{3}$ Clinical Trials Unit, Istituto Nazionale per lo Studio e la Cura dei Tumori - Fondazione G. Pascale IRCCS, Napoli, Italy.

\section{Corresponding author:}

Prof. Massimo Di Maio

Department of Oncology

University of Turin

San Luigi Gonzaga Hospital

Regione Gonzole 10, 10043 Orbassano (TO), Italy

Phone: +390119026017

Fax: +39 0119015184

Email: massimo.dimaio@unito.it 


\section{Abstract}

Several studies have shown that symptomatic toxicities associated with anti-cancer treatments, such as nausea and vomiting, are frequently under-reported by health care providers, even when prospectively collected within clinical trials. Such under-reporting can produce underestimation of the absolute rate of toxicity, which is highly relevant information for patients and their physicians in clinical practice, as well as for regulatory authorities. Systematic collection of patient-reported outcomes (PROs) has been demonstrated to be a valid, reliable, feasible, and more precise approach to tabulating symptomatic toxicities, compared to health care provider reporting. The U.S. National Cancer Institute has developed a PRO version of the Common Terminology Criteria for Adverse Events (the "PRO-CTCAE") to improve toxicity measurement in clinical trials. The PRO-CTCAE is an item bank with 124 individually validated toxicity questions for patients, with an accompanying software system for directly collecting information about symptomatic adverse events from patients. The barriers and challenges that need to be addressed when considering broad integration of PRO toxicity monitoring in cancer clinical trials are discussed, including challenges related to data collection logistics, analytic approaches, and resource utilization. The advent of instruments like the PRO-CTCAE, conceived to describe therapy side effects from the patient perspective, brings the potential both to improve the quality of data for risk-benefit evaluation in clinical research, and to provide future patients facing treatment decisions with information about prior experiences of their peers. 


\section{Introduction.}

Knowledge regarding potential benefits and risks associated with anticancer therapies is fundamental for making treatment-related recommendations and decisions. This information is key for multiple stakeholders, including regulatory authorities, clinical researchers, physicians, and not least of all for patients. In the regulatory process for the authorization of new medicinal products, both the Food and Drug Administration (FDA) [1] and the European Medicines Agency (EMA) [2] have frameworks for conducting benefit / risk evaluation that rely on qualitative analysis and judgment by experts regarding the available clinical data, classically (but not necessarily) obtained from randomized controlled clinical trials. Benefit is measured in terms of therapeutic efficacy, evaluated according to the primary endpoints for which the studies were designed and powered, such as overall survival or progression free-survival [3]. On the other hand, risk assessment, with evaluation of potential harm from anti-cancer therapy, is based largely on toxicity information garnered in the trials, for which the mainstay has been the investigator reporting of adverse events according to the Common Terminology Criteria for Adverse Events (CTCAE) [4]. The CTCAE defines individual adverse event terms and provides a grading scale for severity of each item. Some adverse events may be measureable in terms of laboratory and other exams (e.g. anemia, QT prolongation), and others from direct clinician observation or measurement (e.g. maculo-papular rash, hypertension). However, approximately $10 \%$ of the adverse event items in the CTCAE represent symptomatic toxicities that, in order to be reported, require that the clinician elicits and then grades the subjective experiences of the patient (diarrhea, fatigue, pain). This system is at risk of underestimating subjective toxicities for several reasons, related to physicians' performance or to more complex aspects of interaction and communication between physicians and patients. Further, this indirect method of reporting a patient 
symptom is at risk for errors in interpretation along the way to final codification as a graded CTCAE in the clinical trial database. By definition of the FDA, clinician reported outcomes "involve clinical judgment or interpretation of the observable signs, behaviors, or other physical manifestations thought to be related to a disease or condition, and cannot directly assess symptoms that are known only to the patient" (http://www.fda.gov/Drugs/DevelopmentApprovalProcess/DrugDevelopmentToolsQualifica tionProgram/ucm370262.htm).

Healthcare provider reporting via the CTCAE has been demonstrated to have a low level of inter-rater reliability [5], and to miss up to half of patients' symptoms compared to direct accounts from patients themselves [6]. Moreover, compared to patient reports, healthcare professional toxicity reports are less concordant with global health status [7]. Of course, as described elsewhere, not all toxicities are amenable to patient reporting [8]. In fact, as noted by the FDA [9], subjective experiences such as symptoms are best known by patients and therefore are those optimally reported directly by patients without filtering by a healthcare professional. On the contrary, non-subjective toxicities such as laboratory test-based toxicities (e.g., neutropenia), or observable phenomena (e.g., retinal detachment), are best reported by providers.

Over the past decade, interest has grown in the potential integration of patient-reported outcomes (PROs) as part of routine toxicity data collection and reporting in clinical trials $[6,10]$. A PRO is defined as a measurement about the patient's condition, reported directly from the patient, without interpretation by clinician or anyone else. Symptom items in quality of life (QOL) instruments, validated symptom scales, and more recently a patient reported outcomes version of the CTCAE developed by the U.S. National Cancer Institute provide means for collecting unfiltered information about symptomatic toxicities directly from patients [11]. 
The FDA and EMA have provided guidance on the use of PROs in clinical trials $[9,12]$, and EMA specifically in trials of anticancer drugs [13], further underlining the importance of including the patient's perspective as a standard and essential source of information when evaluating benefits and harms of cancer therapeutics. Of note, FDA advocates that symptoms or other unobservable concepts known only to the patient (e.g., nausea or pain severity) can adequately be measured only by PRO measures. Patient-reported toxicities may have particular value in trials of oral cancer therapies, where outpatient compliance is a known issue; understanding symptomatic toxicities early in development may be useful, because it is known that patients might discontinue medicines with bothersome symptomatic toxicities (e.g., discontinuation of aromatase inhibitors due to arthralgias). Patient reports may also be especially useful in precision medicine and first-in-man trials, where there are limited insights about impact on patients, for example with immune therapies, which have non negligible - and sometimes unpredictable - toxicities.

\section{Agreement between patients and physicians}

The report by cancer patients themselves is widely considered the gold standard for the assessment of symptoms, as patients are in the best position to comment on their own subjective experiences [9,12]. Published studies have consistently demonstrated that health professionals underestimate the incidence and severity of symptoms, when compared with the report by patients [14-17]. More specifically, a number of publications have been focused on the comparison between patients' and physicians' reporting of treatment adverse events experienced by cancer patients, allowing the description of under-reporting by physicians [18-21].

A structured literature review was conducted via Medline including papers published through August 24, 2015 with the search terms (patient OR patients) AND (physician* OR clinician* $^{*}$ OR investigator ${ }^{*}$ OR nurse*) AND cancer AND (report* OR agreement OR 
comparison $O R$ assessment OR evaluation) AND (toxicity OR symptom* OR tolerance OR tolerability), restricting the search strategy to adult patients. Reference lists of selected publications were also reviewed. Of note, the adoption of literature search criteria with reasonable specificity and enough sensitivity to identify all the existing studies describing any form of comparison between patients' and physicians' assessment of toxicity or symptoms is particularly difficult. However, a systematic description of all the existing publications goes beyond the scope of this article, because our aim is to give the readers a convincing evidence of the relevance of under-reporting by health professionals. The main characteristics (aim of the study, setting, number of patients and institutions, instruments used for patients' reporting and health professionals' reporting) and the most relevant results of selected studies comparing report by patients and health care professionals of toxicity or symptoms associated with anti-cancer treatment are summarized in Table 1. Although it is recognized that this may not be an exhaustive list, these papers are representative of the overall literature in this area.

Overall, across studies it was found that clinicians consistently and substantially under-report both the prevalence and severity of patients' symptoms compared to the direct reports from patients themselves. For example, Fromme and colleagues reported that physicians' evaluation of toxicity was inaccurate, when compared to patients' selfreporting, even in the controlled setting of a prospective trial [18]. Those authors analyzed data collected in a prospective clinical trial evaluating weekly calcitriol and docetaxel in patients with metastatic androgen-independent prostate cancer. The authors found that that physician reporting was neither sensitive nor specific in detecting common chemotherapy adverse effects, with a Cohen's kappa coefficient as low as 0.15 , indicating a poor agreement.

In that study by Fromme and colleagues, comparison between patients' and physicians' reporting was based on different instruments. However, even in the several 
studies where comparison between patients' and physicians' reporting has been assessed using the same instrument, results have underlined the risk of under-reporting by physicians. For example, Basch and colleagues prospectively compared reporting of symptom occurrence and severity by cancer patients and clinicians among outpatients with lung and genitourinary cancer [19]. Both patients' and clinicians' reports were based on the CTCAE; the only difference was that items were transcribed unchanged in the questionnaire filled-in by clinicians, while the patient version included identical items with syntactical modifications in order to improve comprehension. For symptoms that can be better "quantified", such as vomiting or diarrhea, agreement was relatively high. However, agreement was low for subjective symptoms such as fatigue and dyspnoea. In a similar study performed in Italy among outpatients undergoing chemotherapy [20], agreement between patients and nurses was generally stronger than those between patients and physicians. Based on these results, the authors suggested that the nurses could be successfully employed in collecting treatment toxicity, because they showed a better performance than doctors in reporting information from the patients.

However, given the prospective design of these latter comparisons, it is worth noting that healthcare professionals, although blinded to patients' answers, were aware that their report would have been subsequently compared with patients' report; it is reasonable that the rate of under-reporting by clinicians, when they are not aware of the comparison with patients' report, could be substantially higher. In a recent pooled analysis of three randomized trials, patients' and clinicians' reporting of six toxicities (anorexia, nausea, vomiting, constipation, diarrhea, and hair loss) experienced during anti-cancer treatment were subsequently compared [21]. Agreement between patients and clinicians was low, and toxicity rates based on physicians' report were consistently lower than those reported by patients themselves. Under-reporting by clinicians ranged from $41 \%$ for nausea to $74 \%$ for appetite loss. 
Although a systematic description of the factors potentially explaining the underreporting of treatment toxicities by health professionals is not available in literature, we listed and commented the most relevant factors in Table 2. Factors are divided in two large groups: in the first group, information about toxicity is correctly acquired but not reported, while in the second group the under-reporting is the consequence of a defect in communication between patients and health professionals.

In some cases, information about treatment toxicity, although not explicitly reported, could have been correctly acquired by health professionals. They could decide not to report the symptoms that were already present before treatment start, or those judged unrelated to treatment but related to previous treatments or to the disease itself. This could be true for some adverse events: for instance, fatigue or appetite loss are commonly related to cancer itself, at least in patients with advanced disease; on the other hand, peripheral neurotoxicity or hair loss could be expression of residual toxicity from previous treatment lines. However, this explanation is far less reasonable for many adverse events, like nausea or vomiting or diarrhea, that could be prudently considered treatment-related in the majority of cases.

Physicians might also pay less attention in reporting mild toxicities, particularly those effects that would not prompt treatment modification or supportive care. However, an accurate evaluation of the risk / benefit ratio of a treatment should be based on a complete reporting of toxicities, including also mild grades, particularly if long-lasting. Furthermore, there are data suggesting that under-reporting can occur even when patients describe severe toxicity [21]. In a previously described study, the analysis limited to patients who reported "very much" toxicity in any cycle, showed that the proportion of under-reporting by physicians was lower, as expected, compared to the analysis of "any grade" toxicity, but was relevant in any case, ranging from $13.0 \%$ for vomiting to $50.0 \%$ for anorexia (Figure 1) $[21]$. 
In other cases (lower half of Table 2), under-reporting could be due to a defect in communication between patients and health professionals, with the latter not acquiring at all the proper information about the occurrence of toxicity. In this case, under-reporting could lead to a risk of sub-optimal management of the symptoms. If a specific toxicity is largely expected with the drug that the patient is receiving, physicians could "paradoxically" pay less attention to its meticulous report. However, at least in principle, also the opposite could be true, because clinicians could be more accurate in asking patients about largely expected toxicities. From this point of view, it is interesting that in the TORCH trial, comparing erlotinib versus cisplatin + gemcitabine as first-line treatment of patients with advanced non-small-cell lung cancer, the rate of under-reporting for nausea, vomiting and diarrhea suggests that physicians are more accurate in reporting those side effects that are expected with each specific treatment (Figure 2) [21]. In detail, the under-reporting of nausea and vomiting was higher with erlotinib than with chemotherapy, that indeed is expected to produce more emesis than erlotinib. On the other hand, the under-reporting of diarrhea was higher with cisplatin + gemcitabine than with erlotinib, that is typically expected to produce more diarrhea than chemotherapy.

Table 2 describes also potential implications for clinical management. If physicians correctly acquire information about a toxicity but simply under-document, the implication for clinical management may be minimal, but there are substantial implications for clinical trial tabulation. Under-reporting of toxicities in clinical trials and resulting publications and drug labels may lead to subsequent patients under-appreciating the impact a product may have on them. Moreover, there is a lost opportunity for adverse event management programs, and compliance may be negatively affected. In contrast, if under-reporting is due to under-detection, for example due to communication barriers between patients and clinicians, it may lead to the risk of both sub-optimal toxicity management and sub-optimal tabulation. 


\section{Incorporation of PROs in toxicity description}

Several barriers exist to integrating PROs into routine toxicity collection in cancer clinical trials, and solutions have been suggested and tested $[6,8]$. In terms of data collection, concerns have been raised that completion rates may be low, particularly from ill or end-stage patients. Feasibility assessments embedded in multiple clinical trials have now demonstrated sustained compliance rates of approximately $90 \%$ during active therapy, including those with impaired performance status [22-24]. Response rates from patients can be optimized through a number of approaches [25]. First, patients are more likely to respond if they know this is an important part of a trial, that the PROs are requested by their doctor and nurse, and that the information will benefit future patients [25]. This message can be conveyed during informed consent and PRO training. Second, questionnaires need to be brief and easy to complete. Third, compliance should be monitored in real-time, with human backup data collection for non-responders, for example via a telephone call. Backup data collection improves compliance rates by about $10 \%$ overall $[23,25]$.

The logistics of PRO data collection have also been evaluated, finding high compliance rates using in-clinic tablet computer or paper questionnaire administration, between-visit web, or between-visit interactive voice response (IVR) automated telephone systems [8]. Investigative team effort at sites is minimal, and is generally restricted to training patients initially and reminding patients to report [26]. When between-visit reporting is employed, a central data management team can take over reminders and troubleshooting to unweight the local team. In prior trials, less than $1 \%$ of site data management time for any given trial has been consumed with these activities $[24,27]$.

In terms of analyses, there is ongoing debate about whether baseline symptom scores should be considered when reporting toxicities. Patients often enter clinical trials 
with baseline symptoms related to their cancer, to prior treatments, or to comorbidities. Patient-reporting detects more of these baseline symptoms than clinicians. PROs therefore offer an opportunity to control for baseline (pre-existing) symptoms in assessments of toxicity, to identify those events most likely not to be preexisting. Indeed, it is common for regulatory agencies to evaluate adverse events using this approach, but less common for investigators when reporting trial results (e.g., when simple cumulative incidence numbers are provided in toxicity tables). The approach to considering baseline symptoms is as follows: if a patient enters a trial with grade 2 nausea, and during the trial experienced grade 2 nausea, that toxicity would not be counted in an analysis of cumulative incidence of toxicities (i.e., coded as zero). However, if the patient entered with grade 2 but then reported grade 3 during the trial, that would count as a grade 3 .

Memory degradation is a concern, as recall of symptoms begins to fade within about a week [28]. Therefore, ideally weekly patient reporting will be employed during any period of active treatment in a trial, using electronic data capture whenever possible. However, data collection every 2 to 3 weeks can also be considered if necessary for a particular trial design, with an adjusted recall period (e.g., questionnaire every 2 weeks with recall period over the past two weeks), and with an understanding that some additional measurement error will be introduced [29].

One of the most substantial challenges in this area is reconciliation with investigator reports. As noted above, patient and clinician reports of symptomatic toxicities are often discrepant. There is no current consensus on the best approach to reconciliation, and several approaches have been suggested. One approach (Figure 3, panel A) is to share patient reports with investigators in real time at the point of care, so that investigators can make use of that information in the clinical management of the patient. In fact, this approach has been tested in prior clinical trials finding that patient-investigator agreement jumps to more than $90 \%$ [30]. Alternatively, patient and investigator reports can be 
collected separately and reconciled at the time of analysis (Figure 3, panel B), with site queries and selection of the worst report of the two at any given time. If this approach is employed, ideally the baseline scores will be considered in the analysis as described above. A third potential approach (Figure 3, panel C) is to collect the information separately and not reconcile it, but simply report the patient and investigator reports side by side. Of these alternatives, the method with the greatest current interest combines options $\mathrm{B}$ and $\mathrm{C}$, and involves sharing patient reports with investigators at the point of care, but also presenting patient and investigator reports separately.

The final challenge relates to research culture and historical precedent. Patients have not traditionally self-reported toxicities, and there are some investigators who believe that patients might exaggerate or underestimate their own symptom burdens. This perspective is not consistent with current regulatory thinking or with empiric evidence [9, 12-13].

\section{PRO-CTCAE}

In order to bring the patient perspective into toxicity reporting on oncology, in 2008 the U.S. National Cancer Institute began developing a PRO version of the CTCAE [23]. The PRO-CTCAE was developed by a group of multidisciplinary collaborators under a contract to the $\mathrm{NCl}$, with substantial input from the $\mathrm{NCl}$ and FDA. The PRO-CTCAE consists of a library of 78 toxicities mapped to the CTCAE, with up to three patient questions per toxicity. The patient questions were developed with extensive qualitative patient input including cognitive interviewing [5], as well as quantitative evaluation of measurement properties [31,32]. PRO-CTCAE items perform well overall, and equivalence has been found between paper, web, and automated telephone administration of these items. In addition to English, translations currently exist in Spanish, German, Danish, Italian, and Japanese, with additional translations in progress. 
Recent evidence presented at the ISOQOL international meetings in 2014 and 2015 report that the PRO-CTCAE better delineates symptomatic adverse events between study arms based on findings from multicentre cooperative group research, with statistically significant differences between study arms found for substantially more adverse events with patient reporting rather than clinician reporting [23]. Additionally, in evaluations in which patient-reported toxicities were shared with investigators, those investigators' CTCAE reports were found to be more in line with patient reports [30, 33]. Moreover, in these evaluations, patient self-reports identified more baseline symptoms than clinics, enabling analyses of which symptoms were emergent during trials.

The totality of this evidence suggests that although clinician CTCAE reporting has clinical value and is feasible, patient reporting brings greater precision, reliability, and validity to adverse symptom detection in clinical research [34]. Nonetheless, this is a nascent area and additional research and development work is warranted. For example, evidence would be useful to inform the selection of PRO-CTCAE items for given populations and contexts; on methods for optimizing response rates particularly from hardto-reach patients; on how to optimally map PRO-CTCAE scores to CTCAE grades; and on how best to include both health-related quality of life (HRQL) tools and the PRO-CTCAE in a given trial.

The PRO-CTCAE approach differs from traditional HRQL measurement, in several ways that have been outlined previously [8]. Briefly, there are over 100 toxicity questions in the item library for the PRO-CTCAE, and these items have been individually validated. The PRO-CTCAE includes questions on phenomena such as lower extremity edema and bed sores, which are generally not included in HRQL tools. PRO-CTCAE questions are intended for frequent regular administration in trials, e.g., weekly, with analyses akin to standard $\mathrm{AE}$ assessment (i.e., the proportion of patients experiencing each maximum grade post-baseline expressed as a proportion) -- versus HRQL which generally includes 
before-after assessments comparing means between study arms. The purpose of the PRO-CTCAE is to assess symptomatic adverse events with greater precision than the CTCAE. Traditional HRQL tools are generally intended to assess treatment benefits between arms post baseline through global scores, or through the assessment of known disease-related symptoms.

PRO-CTCAE is currently being used by numerous early adopters in clinical trials and observational studies, and can be requested through a Materials Transfer Agreement with the $\mathrm{NCl}$. Interested parties can contact the $\mathrm{NCl}$ Outcomes Research Branch for further information (healthcaredelivery.cancer.gov/resource/outcomes.html). Ideally, the PRO-CTCAE will be integrated widely into trials enabling organic development of methods for implementation and analysis within the research community, as occurred for the CTCAE with success in the past.

\section{Conclusions}

Direct reporting of symptomatic toxicities by patients brings the opportunity to improve the precision, reliability, and validity of symptom toxicity reporting in clinical research. This approach can generate information for use by future patients facing treatment decisions about the experiences of patients like them who participated in clinical trials. The U.S. National Cancer Institute recently developed a patient-reported outcomes version of the Common Terminology Criteria for Adverse Events (PRO-CTCAE), which offers a tangible approach to enhance the "patient-centeredness" of oncology clinical trials and drug development. 


\section{Key points}

- The report by cancer patients themselves is widely considered the gold standard for the assessment of symptoms, as patients are in the best position to comment on their own subjective experiences.

- Published studies demonstrate that health professionals underestimate the incidence and severity of symptoms, when compared with the direct report by patients.

- There is a growing movement toward the integration of patient-reported outcomes as part of routine toxicity data collection and reporting in clinical trials.

- The U.S. National Cancer Institute recently developed a patient-reported outcomes version of the Common Terminology Criteria for Adverse Events (PRO-CTCAE) which may enhance the precision, reliability, and validity of symptomatic toxicity evaluation in cancer clinical research. 
Table 1. Selected studies comparing patients' and physicians' reporting of toxicity associated with anti-cancer treatment.

\begin{tabular}{|c|c|c|c|c|c|c|c|}
\hline $\begin{array}{l}\text { Author } \\
\text { [year] }\end{array}$ & Aim of the study & Setting & $\begin{array}{l}\text { Instrument } \\
\text { used for } \\
\text { patients' } \\
\text { reporting }\end{array}$ & $\begin{array}{l}\text { Instrument } \\
\text { used for } \\
\text { physicians' } \\
\text { reporting }\end{array}$ & $\begin{array}{l}\text { Number } \\
\text { of } \\
\text { patients }\end{array}$ & $\begin{array}{l}\text { Number of } \\
\text { institutions }\end{array}$ & Main results \\
\hline $\begin{array}{l}\text { Fellowes } \\
{[2001]^{35}}\end{array}$ & $\begin{array}{l}\text { To describe discrepancies } \\
\text { between patient- } \\
\text { reported and clinician- } \\
\text { recorded } \\
\text { profiles }\end{array}$ & $\begin{array}{l}\text { Patients with } \\
\text { early breast } \\
\text { cancer } \\
\text { receiving } \\
\text { adjuvant } \\
\text { hormonal } \\
\text { treatment }\end{array}$ & Interview & $\begin{array}{l}\text { Not } \\
\text { specified } \\
\text { (Data } \\
\text { reported in } \\
\text { medical } \\
\text { notes) }\end{array}$ & 72 & 10 & $\begin{array}{l}\text { Significant } \\
\text { under-reporting } \\
\text { in medical notes } \\
\text { for many side } \\
\text { effects. }\end{array}$ \\
\hline $\begin{array}{l}\text { Fromme } \\
\text { [2004] }^{15}\end{array}$ & $\begin{array}{l}\text { To compare } \\
\text { patients'reporting in QoL } \\
\text { questionnaires } \\
\text { physicians reporting of } \\
\text { toxicity }\end{array}$ & $\begin{array}{l}\text { Patients with } \\
\text { advanced } \\
\text { prostate } \\
\text { cancer } \\
\text { enrolled in a } \\
\text { phase II trial }\end{array}$ & $\begin{array}{l}\text { EORTC QLQ- } \\
\text { C30 }\end{array}$ & $\begin{array}{l}\mathrm{NCl}-\mathrm{CTC} \\
\text { version } 2.0\end{array}$ & 37 & 2 & $\begin{array}{l}\text { Physician } \\
\text { reporting was } \\
\text { neither sensitive } \\
\text { nor specific in } \\
\text { detecting } \\
\text { common } \\
\text { chemotherapy } \\
\text { adverse effects. }\end{array}$ \\
\hline
\end{tabular}




\begin{tabular}{|c|c|c|c|c|c|c|c|}
\hline $\begin{array}{l}\text { Basch } \\
{[2006]^{16}}\end{array}$ & $\begin{array}{l}\text { To compare the reporting } \\
\text { of symptom severity } \\
\text { reported by patients and } \\
\text { clinicians }\end{array}$ & $\begin{array}{l}\text { Consecutive } \\
\text { outpatients } \\
\text { with lung or } \\
\text { genitourinary } \\
\text { cancers }\end{array}$ & $\begin{array}{l}\text { Modified } \\
\text { CTCAE } \\
\text { (questionnaire } \\
\text { with } \\
\text { common } \\
\text { CTCAE } \\
\text { symptoms, in a } \\
\text { simplified } \\
\text { language) }\end{array}$ & CTCAE & 400 & 1 & $\begin{array}{l}\text { For most } \\
\text { symptoms, } \\
\text { agreement } \\
\text { between patient } \\
\text { and clinician was } \\
\text { high. Agreement } \\
\text { was higher for } \\
\text { symptoms that } \\
\text { could be } \\
\text { observable } \\
\text { directly, such as } \\
\text { vomiting and } \\
\text { diarrhoea, than } \\
\text { for } \\
\text { subjective more } \\
\text { symptoms, such } \\
\text { as fatigue and } \\
\text { dyspnoea. }\end{array}$ \\
\hline $\begin{array}{l}\text { Basch } \\
\text { [2009] }^{7}\end{array}$ & $\begin{array}{l}\text { To compare how patient's } \\
\text { vs clinician's reports relate } \\
\text { to sentinel clinical events } \\
\text { (deaths, emergency room) }\end{array}$ & $\begin{array}{l}\text { Lung cancer } \\
\text { patients }\end{array}$ & $\begin{array}{l}\text { Modified } \\
\text { CTCAE }\end{array}$ & CTCAE & 163 & 1 & $\begin{array}{l}\text { Patients } \\
\text { generally } \\
\text { reported } \\
\text { symptoms } \\
\text { earlier and more } \\
\text { frequently than } \\
\text { clinicians. }\end{array}$ \\
\hline
\end{tabular}




\begin{tabular}{|c|c|c|c|c|c|c|c|}
\hline $\begin{array}{l}\text { Cirillo } \\
\text { [2009] }^{17}\end{array}$ & $\begin{array}{l}\text { To compare symptoms } \\
\text { collected by patient with } \\
\text { symptoms recorded by } \\
\text { either the clinician or the } \\
\text { nurse }\end{array}$ & $\begin{array}{l}\text { Consecutive } \\
\text { outpatients }\end{array}$ & $\begin{array}{l}\text { Modified } \\
\text { CTCAE } \\
\text { (questionnaire } \\
\text { with } \\
\text { common } \\
\text { CTCAE } \\
\text { symptoms, in a } \\
\text { simplified } \\
\text { language) }\end{array}$ & $\begin{array}{l}\text { CTCAE } \\
\text { (Physicians } \\
\text { / nurses) }\end{array}$ & 85 & 1 & $\begin{array}{l}\text { With the } \\
\text { exception of } \\
\text { nausea (showing } \\
\text { a good } \\
\text { agreement with } \\
\text { patients' reports } \\
\text { for both } \\
\text { physicians and } \\
\text { nurses), } \\
\text { agreements } \\
\text { between patients } \\
\text { and nurses were } \\
\text { generally } \\
\text { stronger than } \\
\text { those between } \\
\text { patients and } \\
\text { physicians }\end{array}$ \\
\hline $\begin{array}{l}\text { Novello } \\
{[2014]^{36}}\end{array}$ & $\begin{array}{l}\text { To describe discrepancy } \\
\text { between patients and } \\
\text { clinicians' perception of } \\
\text { toxicities associated with } \\
\text { targeted therapies for } \\
\text { NSCLC }\end{array}$ & $\begin{array}{l}\text { Patients with } \\
\text { advanced } \\
\text { NSCLC } \\
\text { treated with } \\
\text { targeted } \\
\text { drugs. }\end{array}$ & $\begin{array}{l}\text { Modified } \\
\text { CTCAE } \\
\text { (questionnaire } \\
\text { with } 7 \text { common } \\
\text { CTCAE } \\
\text { symptoms, in a } \\
\text { simplified } \\
\text { language) }\end{array}$ & $\begin{array}{l}\text { CTCAE } \\
\text { version } 4.0\end{array}$ & 133 & 7 & $\begin{array}{l}\text { Underestimation } \\
\text { of toxicities by } \\
\text { clinicians when } \\
\text { compared with } \\
\text { patients, with a } \\
\text { greater } \\
\text { difference for } \\
\text { adverse events } \\
\text { more strongly } \\
\text { associated with } \\
\text { daily life and } \\
\text { QoL. }\end{array}$ \\
\hline
\end{tabular}




\begin{tabular}{|c|c|c|c|c|c|c|c|}
\hline $\begin{array}{l}\text { Gravis } \\
{[2014]^{37}}\end{array}$ & $\begin{array}{l}\text { To investigate differences } \\
\text { between patients and } \\
\text { clinicians reporting of } \\
\text { treatment-related toxicity. }\end{array}$ & $\begin{array}{l}\text { Patients with } \\
\text { advanced } \\
\text { prostate } \\
\text { cancer } \\
\text { enrolled in a } \\
\text { phase III trial }\end{array}$ & $\begin{array}{l}\text { Questionnaire } \\
\text { about } 26 \\
\text { symptoms } \\
\text { commonly } \\
\text { associated with } \\
\text { docetaxel and } \\
\text { castration }\end{array}$ & $\begin{array}{l}\text { CTCAE } \\
\text { version } 3.0\end{array}$ & 220 & 30 & $\begin{array}{l}\text { High rate of } \\
\text { under-reporting by } \\
\text { physicians, even } \\
\text { for the most } \\
\text { common and } \\
\text { disturbing } \\
\text { symptoms. }\end{array}$ \\
\hline $\begin{array}{l}\text { Di Maio } \\
{[2015]^{18}}\end{array}$ & $\begin{array}{l}\text { To compare reporting by } \\
\text { patients and physicians of } \\
\text { six toxicities. }\end{array}$ & $\begin{array}{l}\text { Patients with } \\
\text { early breast } \\
\text { cancer or } \\
\text { advanced } \\
\text { lung cancer } \\
\text { enrolled in } \\
\text { three phase } \\
\text { III trials }\end{array}$ & $\begin{array}{lr}\begin{array}{l}\text { EORTC } \\
\text { C30 }\end{array} & \begin{array}{r}\text { QLQ- } \\
\text { (all } \\
\text { patients), } \\
\text { EORTC }\end{array} \\
\text { LC13 } & \text { QLQ- } \\
\text { cancer) } & \\
\text { EORTC } & \text { QLQ- } \\
\text { BR23 } & \text { (breast } \\
\text { cancer) } & \end{array}$ & $\begin{array}{l}\mathrm{NCl}-\mathrm{CTC} \\
\text { version } 2.0 \\
\text { or } \\
\text { CTCAE } \\
\text { version } 3.0\end{array}$ & 1090 & 78 & \begin{tabular}{lr}
\multicolumn{2}{l}{ Agreement } \\
between patients \\
and physicians \\
was low for all \\
toxicities. \\
Toxicity rates \\
reported by \\
physicians were \\
always lower \\
than those \\
reported by \\
patients.
\end{tabular} \\
\hline $\begin{array}{l}\text { Montemurro } \\
{[2015]^{38}}\end{array}$ & $\begin{array}{l}\text { To compare reporting by } \\
\text { patients and physicians of } \\
10 \text { chemotherapy-related } \\
\text { side effects. }\end{array}$ & $\begin{array}{l}\text { Patients } \\
\text { undergoing } \\
\text { adjuvant } \\
\text { chemotherapy } \\
\text { for early } \\
\text { breast cancer }\end{array}$ & $\begin{array}{l}\text { Italian } \\
\text { translation of } \\
\text { CTCAE v4.02 }\end{array}$ & $\begin{array}{l}\text { CTCAE } \\
\text { v4.02 }\end{array}$ & 610 & 11 & $\begin{array}{l}\text { Frequency of } \\
\text { chemotherapy- } \\
\text { related side } \\
\text { effects was } \\
\text { systematically } \\
\text { higher in } \\
\text { patients' reports } \\
\text { than in } \\
\text { physicians' } \\
\text { reports, as was } \\
\text { the grade of } \\
\text { severity. }\end{array}$ \\
\hline
\end{tabular}

NSCLC: non-small cell lung cancer; QoL: quality of life; EORTC: European Organization for Research and Treatment of Cancer; QLQ: Quality of Life questionnaire; NCI-CTC: National Cancer Institute - Common Toxicity Criteria; CTCAE: Common Terminology Criteria for Adverse Events. 


\begin{tabular}{|c|c|c|}
\hline & & $\begin{array}{l}\text { Associated Risk of } \\
\text { Sub-optimal Clinical } \\
\text { Management } \\
\text { Toxicities }\end{array}$ \\
\hline \multicolumn{3}{|c|}{ Information about toxicity correctly acquired but not reported } \\
\hline Pre-existing symptoms & $\begin{array}{l}\text { Physicians could decide not to report those symptoms already } \\
\text { present before treatment start, if considered unrelated to treatment } \\
\text { but related to previous treatments or to disease itself. } \\
\text { The symptom is correctly acquired, so risk of sub-optimal treatment } \\
\text { is low. }\end{array}$ & $+/-$ \\
\hline $\begin{array}{l}\text { Symptoms attributed to the } \\
\text { disease itself }\end{array}$ & $\begin{array}{l}\text { Even if the symptoms were not present before treatment start, } \\
\text { physicians could decide not to report those symptoms if considered } \\
\text { related to disease itself. } \\
\text { The symptom is correctly acquired, so risk of sub-optimal treatment } \\
\text { is low. }\end{array}$ & $+/-$ \\
\hline $\begin{array}{l}\text { Mild symptoms / } \\
\text { Symptoms not needing } \\
\text { intervention }\end{array}$ & $\begin{array}{l}\text { Physicians could pay less attention in reporting mild symptoms or } \\
\text { those symptoms that do not need treatment modification } \\
\text { (interruption, delay, dose reduction) or supportive treatments. } \\
\text { Risk of sub-optimal treatment is present but low. }\end{array}$ & $+/-$ \\
\hline $\begin{array}{l}\text { Toxicities correctly reported in } \\
\text { patient's file, but not in study case } \\
\text { report form. }\end{array}$ & $\begin{array}{l}\text { Physicians could correctly report the occurrence of toxicity in } \\
\text { patient's clinical file, but not in study case report form. } \\
\text { This under-reporting would affect the quality of study results and } \\
\text { future communication between physicians and patients in clinical } \\
\text { practice, but it will not necessarily affect the management of that } \\
\text { patient in clinical practice. }\end{array}$ & - \\
\hline \multicolumn{3}{|c|}{ Defect in communication between patient and physician } \\
\hline Side effects largely expected & $\begin{array}{l}\text { Physicians could be less likely to report a toxicity that is largely } \\
\text { expected (and "routinely" managed) with the specific drug. } \\
\text { The routine management could be the reason for under-reporting, so } \\
\text { the risk of sub-optimal treatment is reasonably low. }\end{array}$ & $+/-$ \\
\hline Unusual side effects & $\begin{array}{l}\text { Physicians could be less likely to ask patients about the occurrence } \\
\text { of a toxicity that is not commonly expected with the specific drug. }\end{array}$ & + \\
\hline
\end{tabular}




\begin{tabular}{|l|l|l|}
\hline & $\begin{array}{l}\text { This would determine under-reporting as well as risk of sub-optimal } \\
\text { management of toxicity. }\end{array}$ & \\
\hline Toxicity not referred by patients & $\begin{array}{l}\text { If not part of a systematic assessment, toxicity will be reported only if } \\
\text { specifically asked by the physician, or spontaneously reported by the } \\
\text { patient. } \\
\text { If the communication is defective, this will imply a substantial risk of } \\
\text { sub-optimal management of toxicity. }\end{array}$ & ++ \\
\hline
\end{tabular}




\section{Competing interests}

EB has received research funding from the U.S. National Cancer Institute for developing the PRO-CTCAE.

MDM, JB and FP declare no competing financial interests in relation to the work described. 


\section{References}

1. Food and Drug Administration's Overall risk management activities.

September $16,2009 . \quad$ Available online:

http://www.fda.gov/Safety/SafetyofSpecificProducts/ucm180589.htm. [Last accessed May 26, 2015]

2. European Medicines Agency. Reflection paper on Benefit-Risk Assessment Methods in the Context of the Evaluation of Marketing Authorisation Application of Medicinal Products for Human Use. March 19, 2008. Available online: http://www.ema.europa.eu/docs/en GB/document library/Regulatory and procedur al guideline/2010/01/WC500069634.pdf [Last accessed May 26, 2015]

3. European Medicines Agency. Guideline on the the evaluation of anticancer products in man. December 13, 2012. Available online: http://www.ema.europa.eu/docs/en GB/document library/Scientific guideline/2013/0 1/WC500137128.pdf [Last accessed May 26, 2015].

4. Cancer Therapy Evaluation Program, Common Terminology Criteria for Adverse Events, Version 3.0, March 31, 2003 (http://ctep.cancer.gov), Publish Date: August 9, 2006

5. Atkinson, T.M., et al. Reliability of adverse symptom event reporting by clinicians. Qual Life Res 21:1159-1164 (2012).

6. Basch, E. The missing voice of patients in drug-safety reporting. $N$ Engl $J$ Med. 362, 865-869 (2010). 
7. Basch, E. et al. Adverse symptom event reporting by patients vs clinicians: relationships with clinical outcomes. J Natl Cancer Inst. 101: 1624-1632 (2009).

8. Basch, E. et al. Development of the National Cancer Institute's patientreported outcomes version of the common terminology criteria for adverse events (PRO-CTCAE). J Natl Canc Inst. 106, 9 (2014).

9. U.S. Department of Health and Human Services, Food and Drug Administration. Guidance for Industry: Patient-Reported Outcome Measures: Use in Medical Product Development to Support Labeling Claims. December 2009. Available online:

http://www.fda.gov/downloads/Drugs/GuidanceComplianceRegulatorylnformation/Gui dances/UCM193282.pdf [Last accessed May 26, 2015]

10. Trotti, A., Colevas, A.D., Setser, A. \& Basch, E. Patient-reported outcomes and the evolution of adverse event reporting in oncology. J Clin Oncol. 25, 51215127 (2007).

11. Reeve, B.B., et al. Recommended patient-reported core set of symptoms to measure in adult cancer treatment trials. J Natl Cancer Inst. 106, 7 (2014).

12. European Medicines Agency, Committee for Medicinal Products for Human Use. Reflection paper on the regulatory guidance for the use of health-related quality of life (HRQL) measures in the evaluation of medicinal products. July 27, 2005. Available online: 
http://www.ema.europa.eu/docs/en GB/document library/Scientific guideline/2009/0 9/WC500003637.pdf [Last accessed May 26, 2015]

13. European Medicines Agency. Reflection paper on the use of patient reported outcome measure in oncology studies. June 17, 2014. Available online: http://www.ema.europa.eu/docs/en GB/document library/Scientific guideline/2014/0 6/WC500168852.pdf [Last accessed May 26, 2015]

14. Grossman, S.A., Sheidler, V.R., Swedeen, K., Mucenski, J. \& Piantadosi, S. Correlation of patient and caregiver ratings of cancer pain. J Pain Symptom Manage. 6, 53-57 (1991).

15. Vogelzang, N.J. et al. Patient, caregiver, and oncologist perceptions of cancer-related fatigue: results of a tripart assessment survey. The Fatigue Coalition. Semin Hematol. 34(3 Suppl 2), 4-12 (1997).

16. Litwin, M.S., Lubeck, D.P., Henning, J.M. \& Carroll, P.R. Differences in urologist and patient assessments of health related quality of life in men with prostate cancer: results of the CaPSURE database. J Urol. 159, 1988-1992 (1998).

17. Petersen, M.A., Larsen, H., Pedersen, L., Sonne, N. \& Groenvold, M. Assessing health-related quality of life in palliative care: comparing patient and physician assessments. Eur J Cancer. 42, 1159-1166 (2006).

18. Fromme, E.K. Eilers, K.M., Mori, M., Hsieh, Y.C. \& Beer, T.M. How accurate is clinician reporting of chemotherapy adverse effects? A comparison with patient- 
reported symptoms from the Quality-of-Life Questionnaire C30. J Clin Oncol. 22, 3485-3490 (2004).

19. Basch, E., et al. Patient versus clinician symptom reporting using the National Cancer Institute Common Terminology Criteria for Adverse Events: results of a questionnaire-based study. Lancet Oncol. 7, 903-909 (2006).

20. Cirillo, M., Venturini, M., Ciccarelli, L., Coati, F., Bortolami, O. \& Verlato, G. Clinician versus nurse symptom reporting using the National Cancer InstituteCommon Terminology Criteria for Adverse Events during chemotherapy: results of a comparison based on patient's self-reported questionnaire. Ann Oncol. 20, 19291935 (2009).

21. Di Maio, M. et al. Symptomatic toxicities experienced during anticancer treatment: agreement between patient and physician reporting in three randomized trials. J Clin Oncol. 33, 910-915 (2015).

22. Wu, A.W., Snyder, C., Clancy, C.M. \& Steinwachs, D.M. Adding the patient perspective to comparative effectiveness research. Health Aff (Millwood). 29, 18631871 (2010).

23. Dueck, A., et al. A Cluster-randomized Study of Clinician-patient Shared vs Standard Reporting of Symptomatic Adverse Events using PRO-CTCAE Nested in a Multicenter Trial of Multimodal Therapy for Rectal Cancer (Alliance N1048 PROSPECT). International Society for Quality Of Life Resarch. Vancouver, Canada, 2015. 
24. Basch, E., et al. Feasibility of patient reporting of symptomatic adverse events via the PRO-CTCAE in a Radiation Therapy Oncology Group (RTOG) Cooperative Group Clinical Trial. International Society for Quality of Life Research Quality of Life Research 2014;Vol 23(1) Supplement, pp.1-184.

25. Basch, E. et al. Recommendations for Incorporating Patient-Reported Outcomes Into Clinical Comparative-Effectiveness Research in Adult Oncology. J Clin Oncol. 30, 4249-4255 (2012).

26. Bruner, D.W. et al. Stakeholder Perspectives on Implementing the National Cancer Institute's Patient-Reported Outcomes Version of the Common Terminology Criteria for Adverse Events (PRO-CTCAE). Trans Behav Med. 1, 110-122 (2011).

27. Verstovsek, S., et al. A double-blind, placebo-controlled trial of ruxolitinib for myelofibrosis. N Engl J Med. 366(9):799-807 (2012).

28. Stull, D.E., Leidy, N.K., Parasuraman, B. \& Chassany, O. Optimal recall periods for patient-reported outcomes: challenges and potential solutions. Curr Med Res Opin. 25, 929-942 (2009).

29. Mendoza, T.R., et al. Impact of Recall Period on the Accuracy of Selected Items from the US National Cancer Institute's Patient-Reported Outcomes version of the Common Terminology Criteria for Adverse Events (PRO-CTCAE). International Society for Quality Of Life Research. Berlin, Germany, 2014.

30. Basch, E., Bennett, A., Pietanza, M.C. Use of patient-reported outcomes to improve the predictive accuracy of clinician-reported adverse events. J Natl Cancer Inst. 103(24):1808-1810 (2011). 
31. Hay, J.L. et al; NCI PRO-CTCAE Study Group. Cognitive interviewing of the U.S. National Cancer Institute's Patient-Reported Outcomes version of the Common Terminology Criteria for Adverse Events (PRO-CTCAE). Qual Life Res. 23, 257-269 (2014).

32. Dueck, A.C., et al.; National Cancer Institute PRO-CTCAE Study Group. Validity and Reliability of the US National Cancer Institute's Patient-Reported Outcomes Version of the Common Terminology Criteria for Adverse Events (PROCTCAE). JAMA Oncol. 2015 Aug 13. [Epub ahead of print]

33. Basch, E., et al. Feasibility and clinical impact of sharing patient-reported symptom toxicities and performance status with clinical investigators during a phase 2 cancer treatment trial. Clinical Trials 2015; in press.

34. Movsas, B. PROceeding With the Patient-Reported Outcomes (PROs) Version of the Common Terminology Criteria for Adverse Events. JAMA Oncol. 2015 Aug 13. [Epub ahead of print]

35. Fellowes, D., Fallowfield, L.J., Saunders, C.M., Houghton, J. Tolerability of hormone therapies for breast cancer: how informative are documented symptom profiles in medical notes for 'well-tolerated' treatments? Breast Cancer Res Treat. 66(1):73-81 (2001).

36. Novello, S. et al. Italian multicenter survey to evaluate the opinion of patients and their reference clinicians on the "tolerance" to targeted therapies already 
available for non-small cell lung cancer treatment in daily clinical practice. Trans/ Lung Cancer Res. 3: 173-180 (2014).

37. Gravis, G. et al. Patients' self-assessment versus investigators' evaluation in a phase III trial in non-castrate metastatic prostate cancer (GETUG-AFU 15). Eur J Cancer 50: 953-962 (2014).

38. Montemurro, F. et al. Patient self-evaluation of side-effects related to adjuvant chemotherapy in breast cancer: A prospective study. J Clin Oncol. 33: suppl; abstr 9606 (2015). 


\section{Figure legends}

Figure 1. Relative under-reporting of toxicity by physicians, defined as the proportion of patients with toxicity reported in any of the cycles, but not reported at all by physician. Data are from 1090 patients with advanced lung cancer or early breast cancer, receiving anticancer treatment within 3 randomized controlled trials [based on data from Di Maio et al, J Clin Oncol $\left.2015^{21}\right]$.

Figure 2. Relative under-reporting by physicians of nausea, vomiting and diarrhea in the TORCH trial, comparing chemotherapy (cisplatin + gemcitabine) vs. erlotinib as first-line treatment of patients with advanced non-small cell lung cancer. These data suggest that physicians are more accurate in reporting those side effects that are expected with each specific treatment [based on data from Di Maio et al, J Clin Oncol 2015 ${ }^{21}$ ].

Figure 3. Possible modalities of reconciliation of patient's and physician's report of symptomatic toxicities. Panel A: patient reports are shared with investigators in real time during the visit. Panel B: patient and investigator reports are collected separately and reconciled at the time of analysis. Panel C: patient and investigator reports are collected and reported separately. 